A C T A C H E M I C A S C A N D I N A V I C A 24 (1970) $1883-1893$

\title{
Determination of Activation Parameters in One Kinetic Experiment
}

\author{
PERA H L B E G
}

Department of Organic Chemistry, Umeå University, S-901 87 Umeå, Sweden

\begin{abstract}
The conventional procedure for determination of activation parameters involves the measurement of rate constants at different temperatures. By fitting the theoretical model of the transition state theory to the measured pairs $(k, T)$ the activation parameters can be evaluated. In the present work a new method (Varytemp) has been applied to a pseudo-first order reaction using the polarimeter technique for determination of activation parameters. The method consists of measuring a property of a sample while continuously varying the temperature. From the measurements of the three quantities, the property value, the temperature, and the time, the activation parameters can be evaluated using the computer program named Varytemp. The numerics involved is treated in a separate publication by Wold and Ahlberg; ${ }^{1}$ the computer program Varytemp is carefully described in that publication. The Varytemp method is shown to require much less time and substrate and the accuracy is shown to be much better than that obtained by the conventional procedure. There seem to be many possibilities for developing the method technically and for using it for reacions of other orders than first-order.
\end{abstract}

Tn the beginning of the study of structure-reactivity relationships in a $I_{\text {series of substituted indenes undergoing base catalyzed tautomeric rearrange- }}$ ment a fast routine method for determination of activation parameters was desired. Estimates for activation entropies were wanted with an accuracy of about \pm 0.5 e.u.

The conventional procedure for determination of activation parameters consists of the measurement of rate constants at different temperatures. By fitting the theoretical model of the transition state theory to the measured data pairs $(k, T)$ the free energy of activation $\left(\Delta G^{*}\right)$, the enthalpy of activation $\left(\Delta H^{*}\right)$, and the entropy of activation $\left(\Delta S^{*}\right)$ are determined.2,3 Sometimes even estimates for the temperature dependence of the parameters can be obtained. High accuracy in the parameters can be effected using several $k$ 's with small errors distributed over a large temperature interval., ${ }^{2,3}$

Many substituted indenes have been investigated with respect to activation parameters using both the NMR-technique and the polarimeter technique. ${ }^{4}$

Acta Chem. Scand. 24 (1970) No. 6 
At present the NMR-technique yields far too large errors in the parameters because of the low accuracy of the determined rate constants. The polarimeter technique, however, can yield high accuracy rate constants and the desired accuracy of the parameters can be reached if a large temperature interval and many rate constants are used. This "conventional" method is, however, very time consuming. In this investigation a very accurate routine method which is much faster than the "conventional method", has been developed. This method makes it possible to determine the parameters in one kinetic experiment. A property related to the degree of reaction is measured while continuously varying the temperature.

From the values of the property $(\alpha)$, the temperature $(T)$, and the time $(t)$ which are measured simultaneously during the reaction, the parameters can also be evaluated. Rate constants at desired temperatures can also be determined. Calculation by hand is possible, but the use of a computer is strongly preferred. Parallel to the present work a computer program has been developed to treat the experimental output in a proper way. ${ }^{1}$ The method named Varytemp is demonstrated and tested with the polarimeter technique on the base catalyzed racemization of 1-ethylindene. The conventional and the Varytemp methods have been compared under similar conditions.

\section{EXPERIMENTAL}

The value of a sample property related to the degree of reaction must be measured simultaneously with the temperature of the sample, and varied in the desired way, keeping the temperature gradients in the sample small.

The micro cell shown in Fig. 1 has been used as the sample tube. With this cell it is possible to vary the temperature of the sample continuously by circulating a liquid with continuously varying temperature through the thermostat cover. The small amount of sample and the slow variation of the temperature guarantee small temperature gradients in the sample. Continuous temperature variation of the circulating liquid was achieved by using a reservoir for the large liquid volume and varying the energy output from a heater to the liquid in the reservoir. The sample temperature was measured indirectly

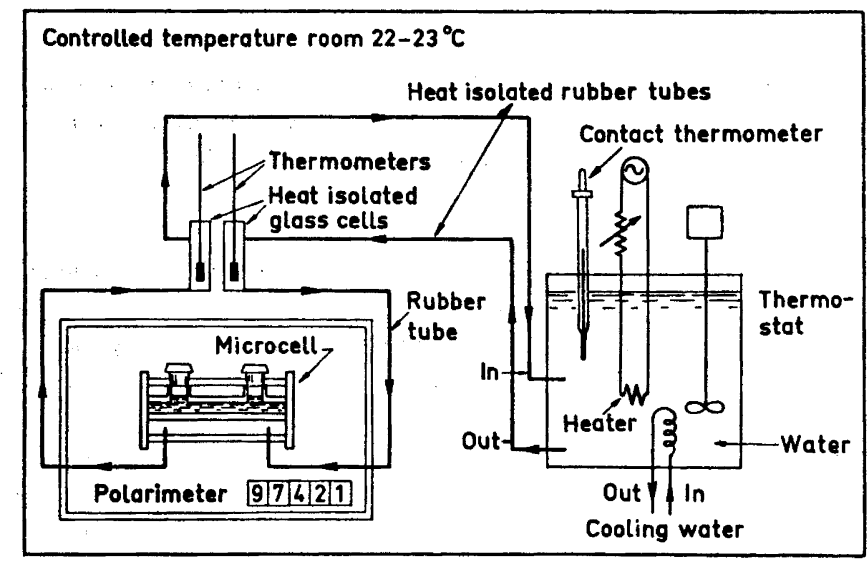

Fig. 1. Schematic view of the apparatus used for the present experiments.

Acta Chem. Scand. 24 (1970) No. 6 
by using two thermometers arranged as in Fig. 1. A polarimeter with digital output was used to measure the varying value of the sample property. The polarimeter technique requires samples which change their rotation with time. The reaction used in this work was the base catalyzed racemization of optically active 1-ethylindene. The racemization is due mainly to the tautomeric rearrangement to symmetric 3-ethylindene (Fig. 2).5 The different parts of the equipment shown in Fig. 1 are described below.

The polarimeter. A Perkin-Elmer 141 polarimeter with the following specifications was used. The measuring accuracy was 0.002 for angles of rotation smaller than 1.000 degree, otherwise $0.2 \%$. Measurements were made with only one of several possible wavelengths. The mercury line at $578 \mathrm{~nm}$ was used.

The micro cell. A $100 \mathrm{~mm}$ micro cell from Perkin-Elmer having a sample volume of $1 \mathrm{ml}$ was used (Fig. 1). The cell was made of special optical glass and had a thermostat cover for use in high accuracy measurements.

The thermostat. A Colora ultra thermostat type NB was used for both constant and variable temperature kinetics. When constant temperature kinetics were studied an extra thermostat was used to control the cooling water in order to balance the heater output. The temperature of the circulating water was controlled within $\pm 0.01^{\circ} \mathrm{C}$.

In some Varytemp experiments a constant voltage was put over one of the heaters in the Colora thermostat as in run 7, Fig. 3. In the other runs (4 and 10) the voltage was changed stepwise to keep $\mathrm{d} T / \mathrm{d} t$ approximately constant. In run $7, \mathrm{~d} T / \mathrm{d} t$ varied between $0.09-0.04^{\circ} \mathrm{C} / \mathrm{min}$ and in the runs 10 and $4 \mathrm{~d} T / \mathrm{d} t$ was approximately equal to $0.06^{\circ} \mathrm{C} / \mathrm{min}$.

Fig. 2. Change of temperature as a function of time in the different Varytemp runs.

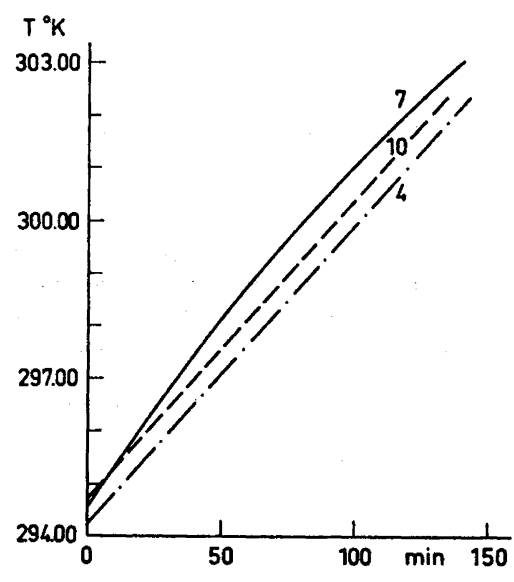

The thermometers. The thermometers were $10^{\circ} \mathrm{C}$ interval thermometers graded in $1 / 100^{\circ} \mathrm{C}$ calibrated by Deutsches Amt für Messwesen und Warenprüfung der Deutschen Demokratischen Republik. The accuracy was $\pm 0.02^{\circ} \mathrm{C}$. The thermometers were from Svenska Termometerfabriken, Gothenburg, Sweden.

The time measurement. A chronometer was used for the time measurements.

The sample temperature measurement. The temperature of the sample was measured indirectly by using two thermometers, each partially dipped in a glass cell, as shown in Fig. 1.

The gradient over the two rubber tubes, which had equal length $(0.5 \mathrm{~m})$, and over the micro cell was measured as the corrected temperature difference between the thermometer readings. This gradient was never more than $0.04^{\circ} \mathrm{C}$ when the temperature interval $20-30^{\circ} \mathrm{C}$ was used, the room temperature being held between 22 and $23^{\circ} \mathrm{C}$.

The gradient over the two rubber tubes was measured in the same way, with the micro cell replaced by a short glass tube. The difference between the two gradients was taken as the gradient over the micro cell. The micro cell gradient was always below $0.01^{\circ} \mathrm{C}$, when the temperature interval $20-30^{\circ} \mathrm{C}$ was used and when the room temperature was held in the interval $22-23^{\circ} \mathrm{C}$.

Acta Chem. Scand. 24 (1970) No. 6 
The sample temperature was taken as the corrected reading of the thermometer placed in the flow coming out from the micro cell, plus half the gradient over the rubber tubes and the micro cell.

The gradients were assumed to be the same in constant temperature runs as in Varytemp runs. Thus, the sample temperature in Varytemp runs was evaluated as described above.

Reactants and solvent. Optically active 1-ethylindene was prepared according to Sörlin and Bergson "with one modification; the water elimination was made with $p$ toluenesulfonic acid in benzene. The 1-ethylindene was redistilled twice in vacuum in nitrogen yielding a colorless liquid which was stored under nitrogen in a freezing box.

The base catalyzing the racemization, was triethylenediamine (Kebo AB, Stockholm). The amine was recrystallized three times from hexane (spectrograde), dried in vacuum over phosphorus pentoxide, and stored in a glass stoppered flask over the same drying agent.

Benzene (Merck p.a.) was used as the solvent. The benzene was dried over calcium hydride. The solvent did not racemize the indene with any significant rate as demonstrated by a test experiment.
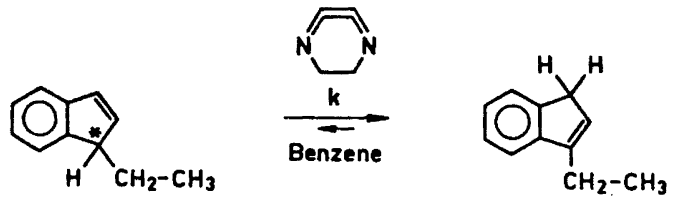

Fig. 3. Reaction and reaction conditions used in the present investigation.

One solution was used for all the kinetic experiments described in the present work. The solution was prepared at $24^{\circ} \mathrm{C}$ and was $1.005 \mathrm{M}$ with respect to 1-ethylindene, 0.0627 $M$ with respect to triethylenediamine. The solution had a volume of $10 \mathrm{ml}$ and was stored in liquid nitrogen to avoid racemization.

Kinetics. In a typical Varytemp run the cleaned empty micro cell was put into the position shown in Fig. 1. The thermostat was held at about $19^{\circ} \mathrm{C}$. The frozen reaction solution was warmed with cold water until everything had melted, and then shaken. Somewhat more than $1 \mathrm{ml}$ of the reaction solution was transferred to the micro cell. The solution was allowed to come to thermal equilibrium which was assumed to be reached within the desired accuracy in $10 \mathrm{~min}$. Then the required voltage was put over the heater, the contact thermometer was set at $32^{\circ} \mathrm{C}$, and the balancing cooling water circuit was closed. The temperature and rotation were measured every minute for about two halflife times. After the Varytemp run, the thermostat was arranged for constant temperature kinetics at about $29^{\circ} \mathrm{C}$, and a constant temperature run on the same solution was made. The rotation was measured every minute for about two half-life times. The infinity value was measured when the rotation due to reaction was less than 0.001 degree as calculated.

Starting rotation for both Varytemp and constant temperature runs varied between 4.3 and 3.8 degrees, except after Varytemp runs, where the starting rotation was about 1.0 degree.

All the constant temperature runs were made for about two half-life times.

The same reaction mixture was used in all Varytemp and constant temperature kinetics to minimize the variation between experiments. Constant temperature rate constants, measured at other temperatures than the ones at which the reaction mixture was prepared $\left(24^{\circ} \mathrm{C}\right)$, must be corrected for change in base concentration due to volume expansion. The volume expansion coefficient was measured once on a solution which had undergone a kinetic experiment with the help of a $1 \mathrm{ml}$ pycnometer. The coefficient was found to be $0.00115 \pm 0.00005\left({ }^{\circ} \mathrm{C}\right)^{-1}$ for the reaction mixture. The same temperature interval was used for the coefficient determination as for the kinetics.

When the Varytemp method is used two corrections have to be made when treating the experimental data: 1 . A correction for the change in the base concentration due to 
volume expansion; 2. A correction for the change in the rotation of the solution which is not due to the reaction, but which is dependent on the temperature variation through the experiment.

The change in rotation which is not due to the reaction was determined in a separate experiment with a solution which had the same composition as the reaction solution except that the base was excluded. In a Varytemp run on the solution the temperature dependence of the rotation was measured in the interval $20-30^{\circ} \mathrm{C}$.

The following relation

$$
\alpha=\alpha_{0}\left(1-\gamma_{2}\left(T-T_{0}\right)\right)
$$

describes the dependence, where $\gamma_{2}=0.00165 \pm 0.00004\left({ }^{\circ} \mathrm{C}\right)^{-1}$. In the next part a theory that takes care of the above mentioned corrections is developed for pseudo first order reactions.

\section{THEORY AND BRIEF DESCRIPTION OF THE COMPUTER PROGRAM}

The reaction under study is a pseudo first order reaction as demonstrated in the next part.

The constant temperature runs of conventional procedure have the following rate expression

$$
-\mathrm{d} \alpha(t) / \mathrm{d} t=k_{\mathrm{obs}}(T) \cdot \alpha(t)
$$

Integrated eqn. 1 becomes

$$
\alpha(t)=[\alpha(0)-\alpha(\infty)] \times \exp \left[-k_{\mathrm{obs}}(T) t\right]+\alpha(\infty)
$$

$k_{\text {obs }}(T)$ is related to the rate constant $k(T)$ by

$$
k_{\mathrm{obs}}(T)=k(T) \times B(T)
$$

The change in base concentration $(B(T))$ with temperature which is due to volume expansion, is described by

$$
B(T)=B_{0}\left[1-\gamma_{1}\left(T-T_{0}\right)\right]
$$

The symbol 0 refers to $T_{0}$ conditions. The temperature at which the reaction solution was prepared has been chosen as $T_{0}$. Insertion of eqn. 4 in eqn. 3 yields

$$
k_{\mathrm{obs}}(T)=k(T) B_{0}\left[1-\gamma_{1}\left(T-T_{0}\right)\right]
$$

The computer program Progaexp ${ }^{6}$ has been used to evaluate $k_{\text {obs }}(T)$ from the measured pairs $(\alpha, t)$. Progaexp allows several models to be fitted to the data; two of these have been used here.

Model 1:

$$
\alpha=\alpha_{1} \times \exp \left[-k_{\text {obs }}(T) t\right]+\alpha_{2}
$$

where $\alpha_{2}$ is equal to the measured infinity value.

Model 2:

This is the same as model 1 , except that $\alpha_{2}$ was also allowed to vary together with the other parameters $\alpha_{1}$ and $k_{\text {obs }}(T)$. Progaexp makes use of the Gauss method, an iterative method, for fitting to non-linear curves. The results are summarized in Table 1.

Acta Chem. Scand. 24 (1970) No. 6 
The program Varytemp was used in the evaluation of the activation parameters (see below).

The experimental output from the Varytemp procedure consists of many sets of values for the three quantities $\alpha, T$ and $t$.

The change of $\alpha(t, T)$ is mainly due to the reaction but has also a small component due to the change of temperature. A model is desired that describes the change of $\alpha(t, T)$ caused only by the reaction. Eqn. 6 has this property

$$
-\frac{\partial \alpha_{0}(t, T)}{\partial t} \times \frac{1}{\alpha_{0}(t, T)}=k_{\text {obs }}(T)
$$

Eqn. 6 will now be expressed in measurable quantities. The following equality holds

$$
-\frac{\partial \alpha(t, T)}{\partial t}=-\frac{\mathrm{d} \alpha(t, T)}{\mathrm{d} t}+\frac{\partial \alpha(t, T)}{\partial T} \times \frac{\mathrm{d} T}{\mathrm{~d} t}
$$

Division by $\alpha(t, T)$ yields

$$
-\frac{\partial \alpha(t, T)}{\partial t} \times \frac{1}{\alpha(t, T)}=-\frac{\mathrm{d} \alpha(t, T)}{\mathrm{d} t} \times \frac{1}{\alpha(t, T)}+\frac{1}{\alpha(t, T)} \times \frac{\partial \alpha(t, T)}{\partial T} \times \frac{\mathrm{d} T}{\mathrm{~d} t}
$$

As demonstrated in the experimental part the dependence of $\alpha(t, T)$ on temperature can be described by

$$
\alpha(t, T)=\alpha_{0}(t, T)\left[1-\gamma_{2}\left(T-T_{0}\right)\right]
$$

Substitution of eqn. 9 in eqn. 8 gives

$$
-\frac{\partial \alpha_{0}(t, T)}{\partial t} \times \frac{1}{\alpha_{0}(t, T)}=-\frac{1}{\alpha(t, T)} \times \frac{\mathrm{d} \alpha(t, T)}{\mathrm{d} t}-\frac{\gamma_{2}}{\left[1-\gamma_{2}\left(T-T_{0}\right)\right]} \times \frac{\mathrm{d} T}{\mathrm{~d} t}
$$

Substitution of eqn. 4 in eqn. 10 yields

$$
-\frac{1}{\alpha(t, T)} \times \frac{\mathrm{d} \alpha(t, T)}{\mathrm{d} t}-\frac{\gamma_{2}}{\left[1-\gamma_{2}\left(T-T_{0}\right)\right]}-\frac{\mathrm{d} T}{\mathrm{~d} t}=k(T) B_{0}\left[1-\gamma_{1}\left(T-T_{0}\right)\right]
$$

$\gamma_{1}$ and $\gamma_{2}$ are measured in separate experiments as described in the experimental part.

With the help of the computer program Varytemp ${ }^{1}$ the left hand side of eqn. 11 was calculated. The derivative was calculated for each measured pair of values of $\alpha$ and $t$. A third degree polynomial was fitted by means of the least squares method to thirty-one measured sets of values of $\alpha$ and $t$. From the derivative of the polynomial, the derivative at the 16th point was evaluated. A smoothed value of $\alpha$ was calculated from the polynomial of the 16th point. The same procedure was used for the measured values of $(T, t)$ yielding the derivative $\mathrm{d} T / \mathrm{d} t$ and a smoothed $T$ value. For the calculation of the activation parameters the program Varytemp ${ }^{1}$ makes use of a Taylor expansion of the logarithm of $k(T)$, treating $\log _{\mathrm{e}} k$ as a function of $1 / T$, around $1 / T_{0}$. The Taylor expansion is fitted to the pairs (smoothed $T$, left hand side of eqn. 11) by means of the Gauss method for non linear curve fitting. From the parameters resulting from the curve fitting the activation 
parameters are evaluated, assuming that the transition state theoretical expression

$$
k(T)=\varkappa(k T / h) \mathrm{e}^{\Delta S^{*}(T) / R} \mathrm{e}^{-\Delta H^{*}(T) / R T}
$$

with $x=1$ holds for the reaction.

The values of the left hand side of eqn. 11 are rate constants at different temperatures. The computer output also contains calculated rate constants at five preselected temperatures.

By using different number of terms in the Taylor expansion the following different models resulted.

Model A: Assumes temperature independence of the activation parameters.

Model B: Assumes temperature dependence in terms of a constant derivative $\mathrm{d} \Delta H^{*} / \mathrm{d}(\mathrm{l} / T)$.

Model C: Assumes also temperature dependence of the derivative $\mathrm{d} \Delta H^{*} / \mathrm{d}(\mathrm{l} / T)$.

The data are treated with all three models but only model $\mathrm{A}$ was found to be significant for the present purpose because of the small temperature interval used and also because of some other reasons explained in the next section.

For a thorough treatment of the numerics refer to Wold and Ahlberg. ${ }^{1}$

\section{EXPERIMENTAL RESULTS AND DISCUSSION}

Columns $1-12$, Table 1 , summarize the results from different constant temperature measurements and rate constants calculated from the different Varytemp runs at the same temperatures as the constant temperature runs were performed.

The rate constants have not been corrected for the volume expansion. As mentioned in the experimental part, the rate constants have been calculated with two models. In model $1, \alpha_{2}$ was fixed and equal to the measured infinity value. In model $2, \alpha_{2}$ was allowed to vary together with the other parameters; $\alpha_{2}$ 's are also tabulated. The program Progaexp also allows calculation of the number of sign changes of the residuals together with an estimation of a sign change interval using the assumption of correct model and random errors. The start and end rotations of the runs are also tabulated. All the errors tabulated are estimated $\pm 2 \sigma$. The temperature of the different runs never varied more than $\pm 0.01^{\circ} \mathrm{C}$ at most. The temperature errors tabulated are the errors in the absolute temperature. Runs 9 and 12 are the only runs that within the error limits give equal results with models 1 and 2 . This fact demonstrates strictly pseudo first order kinetics. All the other runs give rate constants outside the error limits of the meanvalue of the rate constants calculated with the two models. Excluding runs 5 and 11 all the others with model 2 give $\alpha_{2}$ 's which are much larger than the measured $0.002 \pm 0.002^{\circ}$ (except runs 9 and 12). The deviation between rate constants calculated with the two models can be as large as $1.5 \%$ when the estimated precisions are $0.05 \%$ and $0.2 \%$, respectively, run 8 excluded. The number of sign changes are in all cases much below the estimated sign change interval. But the residuals occur (for both models) within the specifications of the polarimeter. The conclusion is

Acta Chem. Scand. 24 (1970) No. 6 
Table 1. Calculated values of rate

\begin{tabular}{|c|c|c|c|c|c|}
\hline 1 & 2 & 3 & 4 & 5 & 6 \\
\hline $\begin{array}{l}\text { Numbers giv- } \\
\text { ing the order } \\
\text { between the } \\
\text { runs, and the } \\
\text { type of } \\
\text { experiment }\end{array}$ & $\begin{array}{c}\text { Temperature } \\
\left.{ }^{\circ} \mathrm{C}\right)\end{array}$ & $\begin{array}{c}\text { Model 1 } \\
k_{\text {obs }} \times 10^{3} \\
(\min )^{-1} \\
\text { calculated } \\
\text { with Model 1 } \\
\text { with } \alpha_{2}=0.002 \\
\pm 0.002\end{array}$ & $\begin{array}{c}\text { Model } 1 \\
\text { Number of } \\
\text { sign changes } \\
\text { of the } \\
\text { residuals }\end{array}$ & $\begin{array}{c}\text { Models } 1 \text { and } 2 \\
\text { Estimated } \\
\text { interval for the } \\
\text { sign changes } \\
\text { of the } \\
\text { residuals }\end{array}$ & $\begin{array}{c}\text { Models } 1 \text { and } 2 \\
\text { Start rotation } \\
\text { - end rotation. } \\
\text { Rotations } \\
\text { given with } \\
\text { reversed sign } \\
\text { (degrees) }\end{array}$ \\
\hline 1 Constant & & & & & \\
\hline 6 temp. & $\begin{array}{l}19.96 \pm 0.03 \\
21.99 \pm 0.03\end{array}$ & $\begin{array}{l}4.273 \pm 0.001 \\
4.924 \pm 0.001\end{array}$ & $\begin{array}{l}32 \\
49\end{array}$ & $\begin{array}{r}130-165 \\
86-115\end{array}$ & $\begin{array}{l}4.604-1.303 \\
4.452-1.429\end{array}$ \\
\hline 3 & $24.11 \pm 0.03$ & $5.740 \pm 0.002$ & 26 & $74-101$ & $4.480-1.640$ \\
\hline 9 & $26.06 \pm 0.03$ & $6.581 \pm 0.001$ & 45 & $74-101$ & $4.330-1.368$ \\
\hline $\begin{array}{l}12 \text { Constant } \\
\text { temp. after }\end{array}$ & $27.93 \pm 0.03$ & $7.560 \pm 0.002$ & 37 & $60-84$ & $4.158-1.410$ \\
\hline $\begin{array}{l}\text { Varytemp } 4 \\
11 \text { Constent } \\
\text { temp. after }\end{array}$ & $27.98 \pm 0.03$ & $7.534 \pm 0.007$ & 19 & $38-57$ & $1.271-0.619$ \\
\hline $\begin{array}{c}\text { Varytemp } 10 \\
8 \text { Constant } \\
\text { temp. after }\end{array}$ & $29.76 \pm 0.03$ & $8.611 \pm 0.011$ & 24 & $45-66$ & $0.644-0.248$ \\
\hline $\begin{array}{r}\text { Varytemp } 7 \\
2 \text { Constant }\end{array}$ & $29.83 \pm 0.03$ & $8.541 \pm 0.015$ & 22 & $32-50$ & $1.307-0.505$ \\
\hline temp. & $29.90 \pm 0.03$ & $8.560 \pm 0.004$ & 12 & $64-88$ & $3.280-0.890$ \\
\hline
\end{tabular}

that there are some unexpected experimental errors. Some drift in the polarimeter during the different runs and disappearance of solvent during the runs are both plausible errors. Control of the polarimeter also showed a small drift. Earlier pseudo first order kinetics with the polarimeter gave the correct number of sign changes and equal results with the two models.

Runs 5 and 11 both gave negative $\alpha_{2}$ values when the rate constant calculation was performed with model 2 ; these facts could very well be explained by a drift. The number of observations varied between 100 and 300 in the runs tabulated in Table 1.

In columns $10-12$ the rate constants from the Varytemp runs 4, 7, and 10 are tabulated. The rate constants at the lowest temperature differ by only $0.07 \%$ at most; at the highest temperature the deviation is much larger, $0.87 \%$ at most. Closer inspection shows that the trend relative run 7 is larger for run 10 than for run 4. Since runs 4 and 10 are executed under similar conditions, why is there this difference in the trends? The above mentioned errors are very probably also operating in these runs and these errors could well give such experimental results. It should also be noted that the model 1 rate constants, in most cases, agree better with the Varytemp constants than the model 2 rate constants.

In the light of the above anomalies it is very difficult to draw conclusions about how large the temperature gradient is in the sample tube during the different Varytemp runs. However, it must be true that the gradient in 
constants and corrected quantities.

\begin{tabular}{|c|c|c|c|c|c|}
\hline 7 & 8 & 9 & 10 & 11 & 12 \\
\hline $\begin{array}{c}\text { Model } 2 \\
k_{\text {obs }} \times 10^{3} \\
(\min )^{-1} \\
\text { calculated } \\
\text { with Model } 2, \\
\alpha_{2} \text { allowed } \\
\text { to vary }\end{array}$ & $\begin{array}{c}\text { Model 2 } \\
\text { Calculated } \\
\alpha_{2} \\
\text { (degrees) }\end{array}$ & $\begin{array}{c}\text { Model } 2 \\
\text { Number of } \\
\text { sign changes } \\
\text { of the } \\
\text { residuals }\end{array}$ & $\begin{array}{c}k_{\text {obs }} \times 10^{3} \\
(\min )^{-1} \\
\text { calculated } \\
\text { from } \\
\text { Varytemp } \\
4\end{array}$ & $\begin{array}{c}k_{\text {obs }} \times 10^{3} \\
(\min )^{-1} \\
\text { calculated } \\
\text { from } \\
\text { Varytemp } \\
7\end{array}$ & $\begin{array}{c}k_{\text {obs }} \times 10^{3} \\
(\text { min) } \\
\text { calculated } \\
\text { from } \\
\text { Varytemp } \\
10\end{array}$ \\
\hline $\begin{array}{l}4.241 \pm 0.005 \\
4.891 \pm 0.005 \\
5.668 \pm 0.008 \\
6.588 \pm 0.007 \\
7.562 \pm 0.012\end{array}$ & $\begin{array}{r}0.020 \pm 0.003 \\
0.017 \pm 0.003 \\
0.035 \pm 0.004 \\
0.000 \pm 0.003 \\
-0.001 \pm 0.003\end{array}$ & $\begin{array}{l}24 \\
41 \\
37 \\
40 \\
33\end{array}$ & $\begin{array}{l}4.239 \pm 0.006 \\
4.912 \pm 0.006 \\
5.721 \pm 0.006 \\
6.559 \pm 0.007 \\
7.470 \pm 0.010\end{array}$ & $\begin{array}{l}4.240 \pm 0.006 \\
4.918 \pm 0.005 \\
5.716 \pm 0.004 \\
6.549 \pm 0.006 \\
7.452 \pm 0.008\end{array}$ & $\begin{array}{l}4.237 \pm 0.006 \\
4.920 \pm 0.006 \\
5.732 \pm 0.006 \\
6.580 \pm 0.007 \\
7.502 \pm 0.010\end{array}$ \\
\hline $7.720 \pm 0.007$ & $-0.020 \pm 0.008$ & 19 & $7.498 \pm 0.010$ & $7.480 \pm 0.008$ & $7.531 \pm 0.010$ \\
\hline $8.925 \pm 0.058$ & $-0.013 \pm 0.003$ & 37 & $8.474 \pm 0.013$ & $8.448 \pm 0.011$ & $8.520 \pm 0.013$ \\
\hline $8.438 \pm 0.063$ & $0.011 \pm 0.006$ & 37 & $8.513 \pm 0.013$ & $8.486 \pm 0.011$ & $8.560 \pm 0.013$ \\
\hline $8.431 \pm 0.010$ & $0.027 \pm 0.002$ & 27 & $8.552 \pm 0.013$ & $8.525 \pm 0.011$ & $8.599 \pm 0.013$ \\
\hline
\end{tabular}

run 7 was not constant throughout the run because $\mathrm{d} T / \mathrm{d} t$ varied by more than a factor of two throughout the run. In runs 4 and 10 the values of $d T / d t$ was held approximately constant throughout the runs. This fact implies a constant gradient in the sample tube during the runs. A constant gradient is serious when accurate absolute values of rate constants are desired, but if the gradient is small the systematic error can easily be held within the experimental error of rate constants. Further, a small constant gradient affects the parameters very little; the activation enthalpy is almost not affected and the entropy of activation is affected only very little.

Demonstration of the between experimental variability is also given in Table 1 . The rate constant calculated with model 1 for run 9 differs from the corresponding Varytemp 10 rate constant by $0.015 \%$, but the rate constant with the same model for run 12 differs from the corresponding Varytemp run 10 by as much as $0.77 \%$. This fact shows that the between experimental error can be appreciable even when the same solution is used for the runs.

The results from the activation parameter estimations are summarized in Table 2. Columns 14-19 give information about the used temperature interval, the start- and end-rotation, the number of observations used in the Gauss fitting, the number of observations on the first half of the temperature interval and the number of sign changes and the estimated sign change interval.

The activation parameters are collected in columns 20-22. The mean value of the enthalpies for the Varytemp runs are $12.067 \pm 0.058 \mathrm{kcal} / \mathrm{mol}$.

Acta Chem. Scand. 24 (1970) No. 6 
Table 2. Calculated values of activation parameters

\begin{tabular}{|c|c|c|c|c|c|c|}
\hline 13 & 14 & 15 & 16 & 17 & 18 & 19 \\
\hline $\begin{array}{l}\text { The numbers } \\
\text { give the order } \\
\text { between the } \\
\text { experiments. } \\
\text { The type of } \\
\text { experiment }\end{array}$ & $\begin{array}{l}\text { Temperature } \\
\text { interval used } \\
\text { in the } \\
\text { caloulations } \\
\left({ }^{\circ} \mathbf{K}\right)\end{array}$ & $\begin{array}{c}\text { Start rotation } \\
\text { - end rotation. } \\
\text { Rotations } \\
\text { given with } \\
\text { reversed sign } \\
\text { (degrees) }\end{array}$ & $\begin{array}{l}\text { Number of } \\
\text { observations } \\
\text { used in the } \\
\text { Gauss fitting }\end{array}$ & $\begin{array}{c}\text { Number of } \\
\text { observations } \\
\text { on the first } \\
\text { half of the } \\
\text { temperature } \\
\text { interval }\end{array}$ & $\begin{array}{l}\text { Number } \\
\text { of sign } \\
\text { changes } \\
\text { of the } \\
\text { residuals }\end{array}$ & $\begin{array}{l}\text { Estimated } \\
\text { interval } \\
\text { for the sign } \\
\text { changes of } \\
\text { the residuals }\end{array}$ \\
\hline $\begin{array}{l}4 \text { Varytemp } \\
7 \text { Varytemp } \\
10 \text { Varytemp } \\
k \text { 's from runs } \\
1,2,3,6,9,12 \\
\text { calculated } \\
\text { with Model 1 } \\
k \text { 's from runs } \\
1,2,3,6,9,12 \\
\text { calculated } \\
\text { with Model } 2\end{array}$ & $\begin{array}{r}294.21-302.51 \\
294.51-302.56 \\
294.74-302.51 \\
293.12-303.06 \\
293.12-303.06\end{array}$ & $\begin{array}{l}\text { see column } 6 \\
\text { see column } 6\end{array}$ & $\begin{array}{l}145 \\
128 \\
138\end{array}$ & $\begin{array}{l}73 \\
72 \\
70\end{array}$ & $\begin{array}{r}8 \\
13 \\
13\end{array}$ & $\begin{array}{l}61-85 \\
53-75 \\
53-81\end{array}$ \\
\hline
\end{tabular}

The enthalpies in runs 4 and 10 fall well outside the error limits for the mean value above. This implies that the estimated errors are too small. The errors present in the constant temperature runs are probably operating in the Varytemp runs to a varying degree and can very well explain this between variation. With an error of $\pm 0.097 \mathrm{kcal} / \mathrm{mol}$ all Varytemp measurements fall within this interval around the mean value.

From the rate constants obtained with models 1 and 2 , respectively, the activation parameters have been determined and these are also shown in columns 20-22. The model 1 calculated rate constant yield a lower estimated error in the parameters by a factor of 2 , as compared with the model 2 calculated rate constant.

The agreement between the Varytemp procedure and the conventional procedure is very good. The error estimated for the enthalpy (mean value) is about half the estimated error with the conventional procedure (Model 1 calculated rate constants). In the future when the experimental technique is refined with respect to the above mentioned experimental errors, it is not unfair to anticipate errors below $0.04 \mathrm{kcal} / \mathrm{mol}$. If the temperature interval is extended to $30^{\circ} \mathrm{C}$ or more it is reasonable to expect errors around 0.01 $\mathrm{kcal} / \mathrm{mol}$ or perhaps smaller.

Measurements on other systems clearly show that the reproducibility is within the estimated error in the parameters obtained with a single experiment when the above mentioned errors are excluded to a large degree. Table 1 shows that the between experimental error is much larger than the estimated precision; thus the major part of a rate constant error is due to errors before the kinetic experiment, probably due to variable catalyst conc. between experiments. The results from Table 1 also show that the between experi- 
at $25^{\circ} \mathrm{C}$ and rate constants at $20^{\circ}, 25^{\circ}$, and $30^{\circ} \mathrm{C}$.

\begin{tabular}{|c|c|c|c|c|c|}
\hline 20 & 21 & 22 & 23 & 24 & 25 \\
\hline 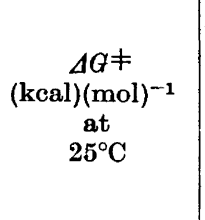 & $\begin{array}{c}\Delta H \neq \\
(\mathrm{kcal})(\mathrm{mol})^{-1} \\
\text { at } \\
25^{\circ} \mathrm{C}\end{array}$ & $\begin{array}{l}\Delta S \neq \\
\text { e.u. } \\
\text { at } \\
25^{\circ} \mathrm{C}\end{array}$ & $\begin{array}{c}\text { Estimation } \\
\text { of } k_{\text {obs }} \times 10^{3} \\
(\mathrm{~min})^{-1} \\
\text { with help of } \\
\text { the program } \\
\text { Varytemp } \\
\text { at } 20^{\circ} \mathrm{C}\end{array}$ & $\begin{array}{c}\text { Estimation } \\
\text { of } k_{\text {obs }} \times 10^{3} \\
(\mathrm{~min})^{-1} \\
\text { with help of } \\
\text { the program } \\
\text { Varytemp } \\
\text { at } 25^{\circ} \mathrm{C}\end{array}$ & $\begin{array}{c}\text { Estimation } \\
\text { of } k_{\text {obs }} \times 10^{3} \\
\text { (min) })^{-1} \\
\text { with help of } \\
\text { the program } \\
\text { Varytemp } \\
\text { at } 30^{\circ} \mathrm{C}\end{array}$ \\
\hline $\begin{array}{l}21.260 \pm 0.0004 \\
21.261 \pm 0.0004 \\
21.259 \pm 0.0006\end{array}$ & $\begin{array}{l}12.057 \pm 0.056 \\
11.981 \pm 0.044 \\
12.164 \pm 0.070\end{array}$ & $\begin{array}{l}-30.87 \pm 0.19 \\
-31.12 \pm 0.15 \\
-30.50 \pm 0.24\end{array}$ & $\begin{array}{l}4.256 \pm 0.0063 \\
4.257 \pm 0.0056 \\
4.254 \pm 0.0063\end{array}$ & $\begin{array}{l}6.091 \pm 0.005 \\
6.084 \pm 0.004 \\
6.107 \pm 0.005\end{array}$ & $\begin{array}{l}8.612 \pm 0.013 \\
8.584 \pm 0.011 \\
8.660 \pm 0.013\end{array}$ \\
\hline $21.256 \pm 0.0022$ & $12.064 \pm 0.200$ & $-30.83 \pm 0.77$ & $4.263 \pm 0.032$ & $6.119 \pm 0.023$ & $8.654 \pm 0.065$ \\
\hline $21.261 \pm 0.0052$ & $12.051 \pm 0.456$ & $-30.89 \pm 1.53$ & $4.248 \pm 0.074$ & $6.078 \pm 0.053$ & $8.592 \pm 0.148$ \\
\hline
\end{tabular}

mental error can be very large. Thus it is correct to conclude that the polarimeter technique is much too good compared with the other errors in base catalyzed reactions when small base concentrations are used. When the parameter determination is made in one experiment, this in between experimental variability is avoided and apparatus precision can be used. It is important to remember that even when the conventional technique is used one must strictly show that the reaction under study has the assumed rate expression. When the Varytemp procedure is used, much time is saved but the property related to the degree of reaction and its temperature dependence must be determined.

Acknowledgements. I am greatly indebted to Professor Göran Bergson and fil. lic. Svante Wold for valuable discussions and advice. I also wish to thank the other members of the group for their constructive interest.

A grant from the Swedish Natural Science Research Council is gratefully acknowledged.

\section{REFERENCES}

1. Wold, S. and Ahlberg, P. Acta Chem. Scand. 24 (1970) 618.

2. Robertson, R. E. Proceedings of Phys. Org. Chem. 4 (1967) 213.

3. Kohnstam, G. Advan. Phys. Org. Chem. 5 (1967) 121.

4. Ohlsson, L., Wold, S. and Bergson, G. Arkiv Kemi 29 (1968) 351.

5. Sörlin, G. and Bergson, G. Arkiv Kemi 29 (1968) 593.

6. Wold, S. Acta Chem. Scand. 21 (1967) 1986.

Received December 3, 1969. 